\title{
PERSONALITY TRAITS AS PREDICTORS OF STRESS AMONG FEMALE TEACHERS IN OSUN STATE TEACHING SERVICE
}

\author{
POPOOLA, Bayode Isaiah PhD \\ $\&$ \\ ILUGBO, Esther Ajoke \\ Department of Educational Foundations and Counselling \\ Obafemi Awolowo University \\ Ile Ife \\ email: bayodep@yahoo.com
}

\begin{abstract}
The paper investigated the stress level of female teachers in Osun State Teaching Service and determined the relationship between stress and each of the personality traits of self concept, extraversion, locus of control and achievement motivation. Using a sample of 370 teachers drawn from 50 randomly selected primary and secondary schools in Osun State, data were collected using four standardized personality instruments and a Stress Assessment Inventory (SAI). The results showed that $80.3 \%$ of female teachers in Osun State Teaching Service had low level of stress; and that there was no significant relationship between stress and each of the personality traits of extraversion $(r=-0.073, p>0.05)$, locus of control $(r=0.047, p>0.05)$; self concept $(r=-0.101 p>0.05)$ and achievement motivation $(r=-0.013 p>0.05)$. The results also showed that marital status of female teachers significantly influenced the stress experienced by them ( $F=3.44$ $p<0.05)$. Specifically, women who were divorced experienced more stress $(\bar{X}=$ 87.00) than those who were single $(\bar{X}=83.97)$ or married $(\bar{X}=77.58)$. The study concluded that personality traits were not substantial predictors of the level of stress experienced by female teachers in Osun State Teaching Service.
\end{abstract}

Key Words: personality, stress, burn-out, job-stress, predictor.

\section{Introduction}

The issue of stress is of great concern among working class people, including women. In the last two decades, stress has continued to attract considerable attention from educational, psychological and social researchers. The term "stress" was first introduced into the fields of 
Personality traits as predictors of stress among female

teachers in 0sun state teaching service

Popoola, B. I. \& Ilugbo, E. A.

Biology and Medicine in 1926 by an Austrian endocrinologist, Hans Selye, working in Montreal, Canada. His concept of stress at that time was a physiological one and throughout his life the psychological component of the phenomenon of stress was not given as much attention as he gave the physiological component. Today, stress has become a complex concept that is difficult to define. A general and popular definition is to characterize it as a process in which environmental forces threaten an individual's well being. Thus, Selye (1974) described the concept as a non-specific response of the body to any demand. The nonspecificity of the response is central to Selye's concept, although many researchers have argued that there may well be far greater specificity than those appreciated.

Schermerhorn, Hunt and Osborn (2005) defined stress as a state of tension experienced by individuals facing extraordinary demands, constraints, or opportunities. Also, Gibson, John and James (1988) defined the concept as a person's adaptive response to a stimulus that places excessive psychological and physical demands on the person. This definition implies two components: first, is the notion of adaptation, which means that people adapt to stressful circumstances in any of several different ways. Second is the role of the stimulus. The stimulus is generally called a stressor. A stressor is anything that induces stress. In addition, the demands placed on the individual by the stressor must be excessive for stress to result and of course, what is excessive for one person may be perfectly tolerable for another. A person must therefore view the demands placed on him or her as excessive for stress to occur.

Teacher stress is specifically defined as a condition of negative effects, such as frustration and anxiety, which results from aspects of the job. According to Gelvin (2007), teacher stress is a response syndrome of negative affects resulting from aspects of a teacher's job and mediated by the perception that the demands constitute a threat to self-esteem and coping mechanisms activated to reduce the perceived threat.

The stress of teaching as an occupation is widespread and crosscultural. As observed by Lhospital and Gregory (2009), teachers today face high stress that can compromise their well-being, longevity in the profession, and the quality of their interactions with students. Consequently, many teachers have been leaving their profession in increasing numbers. In many instances, a high proportion of teachers who remained on their jobs freely admitted their dissatisfaction and rated their jobs as very stressful (Thomas, Clarke \& Lavery, 2003). Wahlund 
and Nerel (1976) found that among white collar occupational groups in Sweden, teachers were the most exposed to job related stress. Kokkinos (2006) reported that primary school teachers in Cyprus were high on emotional exhaustion while their counterparts in the secondary schools were higher on depersonalization. According to Evers, Tomic \& Brouwers (2005) and Kokkinos, Panayiotou \& Dazoglou (2005), negative aspects of the teaching job such as disciplinary problems, students' apathy, overcrowded classrooms, involuntary transfer, inadequate salaries, and lack of administrative support are among the stressors that confront teachers in both developed and developing nations of the world.

In Nigeria, Akande (1989) reported that job-related stress is common among teachers and that the sources of teachers' stress are infinite. Several causes of stress experienced by Nigerian teachers have been identified, some of which include inadequate and inconsistent salaries, over-crowded classes, poor administration, low status of teachers and the monotony of the job (Akande 1989; Balogun 1987). It is obvious that the impact of stress on teachers' job performance and on other areas of life cannot be ignored any longer.

Teacher stress may lead to severe negative consequences such as job absenteeism, teacher turnover, reduced output and health problems. At the personal level, it may result in burnout, which is characterised by emotional exhaustion, depersonalisation and reduced personal accomplishment (Thomas, Clarke \& Lavery, 2003). Teacher stress may also result in educational problems, such as reduced teacher competence (O'Connor \& Clarke, 1990). Undeniably, the problem of teacher stress has social, personal and economic implications.

Various attempts have been made to identify factors that predispose people to stress. Many of such attempts have established a link between the incidence of stress and the personality of individuals. For instance, Akinboye and Adeyemo (2002) found that some people are generally more stress prone while others are generally less stress prone depending on their personality traits. In the same vein, Riolli and Savicki (2003), Readeke and Smith (2004) and Van-Dierendonck (2005) reported that personality characteristics of employees have the tendency to moderate the effect of stressful situations on employees such that certain traits may buffer or enhance more negative outcomes than others. The findings are consistent with those of Kokkinos (2007) who reported that personality characteristics were associated with stress or burnout dimensions, thus providing support for the transactional model of 
Personality traits as predictors of stress among female

teachers in 0sun state teaching service

Popoola, B. I. \& Ilugbo, E. A.

psychological distress in which in order to better understand its process, both environmental and personality variables should be considered.

Nearly everyone experiences psychological distress, or negative effect in actual or perceived stress. Yet people vary widely in the amount of negative affect reported in response to stress, as well as the amount of stress to which they are exposed. Personality variables such as (agreeableness, extraversion, neuroticism, self-concept, etc) have been identified as important predictors of psychological distress (Baghy \& Rector, 1998; Rosenberg \& Pace, 2006). The literature also provides support that an individual's personality characteristic influences the degree to which he or she seeks social support when confronted by a stressful event (Houston \& Zola, 1991).

Some research findings attest to the fact that women are more prone to stress than men. Arroba and James (2002) reported that the relationship between gender and stress is complex and varied and that women are more affected by stress than men. In the same vein, Melhinsh (1998) and Philips \& Segal (1996) concluded that since most women work longer hours than men and both do not share duties equally at home, women tend to experience more psychological symptoms of occupational stress than men.

In Nigeria, various attempts have been made in recent times to reduce job-related stress of teachers. These include an upward review in the salaries of teachers, establishment of various in-service training schemes and the recruitment of more teachers in some states. It is necessary to empirically determine the extent to which these measures have reduced the level of stress experienced by serving teachers. In particular, there is the need for more empirical studies to determine the nature of stress experienced by female teachers as well as identify specific personality traits which are predictors of stress among them. To do this, the present study identified from among the major personality factors in the literature, the personality characteristics of self concept, locus of control, achievement motivation and extraversion as appropriate and relevant for investigation to determine their potency as predictors of stress among female teachers.

From the fore-going submissions, three research hypotheses were postulated:

1. There is no significant relationship between female teachers' level of stress and each of the personality traits 
of extraversion, locus of control, self concept and achievement motivation.

2. The personality variables of self concept, extraversion, locus of control and achievement motivation will not significantly predict the stress level of female teachers.

3. Marital status has no significant influence on the level of stress experienced by female teachers.

\section{Method}

The study adopted the descriptive survey design. The study population consisted of female teachers in Osun State Teaching Service. Statistics from the Nigerian Union of Teachers (NUT) Osun State Chapter showed that there were about 12,000 female teachers in both primary and secondary schools in Osun State as at the end of the 2007/2008 academic session. From this population, a sample of 370 female teachers was selected using the multi-stage sampling procedures. First, ten local government areas were randomly selected from the 30 local government areas in Osun State. After this, five schools (two primary and three secondary schools) were purposively selected from each local government area. To qualify for selection, a school was required to have a minimum of 10 female teachers, out of which a minimum of six was eventually selected. In all, 370 female teachers from 50 schools participated in the study.

\section{Research Instruments}

Five research instruments were used to collect data for the study. These are the Stress Assessment Inventory (SAI) and four personality inventories namely Tennessee Self-Concept Scale (TSCS), Rotter's Internal-External Locus of Control Scale (LCS), Questionnaire Measure of Need Achievement (QMNA) and Eysenck Personality Inventory (EPI).

The Stress Assessment Inventory (SAI) was used in the study to measure the stress level of female teachers. The instrument, which was adapted from Akinboye and Adeyemo (2002), has 40 items measuring four dimensions of stress. Study participants were required to respond to each item of the SAI on a five-point Likert scale ranging from "never present to always present", "very much unlike me to very much like me", "never to always". The responses were scored 1-5 depending on the nature of each item. With this procedure, the minimum and maximum scores obtainable are 40 and 200 respectively. The greater the score a respondent obtained, the more the individual was prone to stress. The 
Personality traits as predictors of stress among female

teachers in 0sun state teaching service

Popoola, B. I. \& Ilugbo, E. A.

instrument was subjected to content validity before its use. In determining its reliability, the test-re-test procedure was adopted. The instrument was administered twice on a sample of 35 teachers at an interval of 2 weeks. This yielded a reliability coefficient of 0.78 , which was considered high enough to justify the use of the instrument in the study.

The Tennessee Self-Concept Scale (TSCS) is a widely used instrument developed by Fitts (1964) to measure the overall perception of an individual about himself or herself. The adapted version of the instrument, which was used in the present study, contained 35 out of the 100 items in the original instrument. The reduction of the items to 35 was to ensure that respondents did not find the scale boring and cumbersome to fill. The sum of a respondent's score in all the 35 items represents his or her total self-concept score. A high score indicates a positive self-concept while a low score is indicative of a negative self-concept. The adapted version of the TSCS has been used and found to be a valid measure of self-concept by many Nigerian researchers including Dibu-Ojerinde (1984), Odeyemi (1995) and Popoola (2003).

The Rotter's Locus of Control Scale (LCS) was adopted in this study to measure respondents' locus of control orientation. The LCS is a widely-used and standardized instrument for measuring locus of control. Rotter (1966) reported that the scale has a relatively stable internal consistency and highly significant construct validity.

Eyo's (1986) adaptation of Herman's (1970) Questionnaire Measure of Need Achievement was used to measure achievement motivation of female teachers in the study. The instrument, which was developed for use in the Nigerian context, has 29 items with seven components. Many Nigerian researchers (Boyinbode, 1988; Odeyemi, 1995; and Popoola, 2003) who have used the instrument to measure achievement motivation of Nigerian subjects, adjudged it to be a valid and reliable instrument for measuring the construct.

The Eysenck Personality Inventory is a standardized and widely used instrument for measuring individuals' placement on the introversion-extroversion continuum. The inventory was first developed by Eysenck (1956) with 24 items on the extraversion sub-scale. Each of the items has three response alternative namely 'Yes', 'No' and 'undecided'. The respondent is expected to tick one of the three response alternatives that is true of each item on the scale. The instrument is scored 1 for 'Yes', 0 for ' $\mathrm{No}^{\prime}$ and $1 / 2$ for undecided. With this procedure, the least obtainable 
score is 0 and the maximum possible score is 24 . The higher the score, the more extraverted a respondent is. The Eysenck Personality Inventory (EPI) is also a standardized inventory of which validity and reliability have been ascertained by its original authors. Some Nigerian researchers have also found sufficient evidence for the reliability of the EPI with Nigerian subjects. (Popoola, 2003).

\section{Data Collection}

The process of data collection for the study started with a visit by the researchers to the selected schools. The questionnaires were administered on the teachers in their schools with the instruction to return them not later than one week. The teachers were reminded that their participation was voluntary and they were not to identify themselves on the questionnaire. The researchers paid a second visit to the schools to collect the completed questionnaires.

\section{Results}

\section{Hypothesis 1:}

This hypothesis states that there is no significant relationship between female teachers' level of stress and each of the personality traits of extraversion, locus of control, self concept and achievement motivation.

In testing the hypothesis, the first step was to determine the respondents' level of stress. This was done using their responses to items on the Stress Assessment Inventory (SAI). Data collected were used to classify respondents into four levels of stress. Respondents who had a score of $0-49$ on the SAI were classified as having "No Stress", those who scored 50-99 were classified as having "Low Stress", respondents who had a score of 100-149 were classified as having "Medium Stress" and those who had a score of 150 - 200 were classified as having "High Stress". Based on this classification, the levels of stress of teachers who participated in the study were determined as shown in Table 1:

Table 1: Stress level of female teachers

\begin{tabular}{|l|c|c|c|c|}
\hline \multicolumn{1}{|c|}{ Level of Stress } & $\mathrm{N}$ & $\%$ & Mean & S.D \\
\hline No Stress & 17 & 4.6 & 42.88 & 2.71 \\
\hline Low Stress & 297 & 80.3 & 74.86 & 13.02 \\
\hline Medium Stress & 53 & 14.3 & 109.43 & 10.41 \\
\hline High Stress & 3 & 0.8 & 161.0 & 9.54 \\
\hline
\end{tabular}


Personality traits as predictors of stress among female

teachers in 0sun state teaching service

Popoola, B. I. \& Ilugbo, E. A.

Table 1 shows that out of 370 female teachers who participated in the study $4.6 \%$ were virtually stress free, $80.3 \%$ had low stress level, $14.3 \%$ had medium stress level while only $0.8 \%$ had high stress level. The implication of this is that a substantial majority of teachers who participated in the study did not experience high level of stress.

The second step in testing hypothesis 1 was to correlate the respondents' scores on the SAI with their scores on each of the personality instruments using Pearson product moment correlation statistics. This was with a view to determining the relationship between teachers' personality characteristics and level of stress experienced by them. The results of this analysis are presented in Table 2 .

As shown in Table 2, the correlation coefficient $(\mathrm{r})$ between stress and extraversion is -.07 . This value is not significant at 0.05 probability level. This suggest that there is an inverse and non-significant relationship between stress and extraversion $(\mathrm{N}=370, r=-.07 \quad \mathrm{p}>0.05)$. Also, the correlation coefficient $(\mathrm{r})$ between stress and Locus of Control is 0.05 . This value is not significant at the 0.05 probability level $(\mathrm{N}=370, \mathrm{r}=$ $0.05, \mathrm{p}>$ >05). In the same vein, the correlation coefficient ( $\mathrm{r}$ ) between stress and Self-Concept is -0.10 . This value is not significant as well at the 0.05 probability level. This also suggests that there is an inverse and not significant relationship between stress and Self-Concept. ( $N=370, r=-$ $0.10, \mathrm{p}>0.05)$.

Table 2: Relationship between stress and personality traits

\begin{tabular}{|c|c|c|c|c|c|}
\hline Variable & $\mathbf{N}$ & $\bar{X}$ & SD & $\mathbf{R}$ & p \\
\hline \multirow{2}{*}{ Stress Extraversion } & 370 & 79.04 & 20.34 & \multirow{2}{*}{-0.07} & \multirow{2}{*}{$>0.05$} \\
\hline & 370 & 53.66 & 8.13 & & \\
\hline \multirow{2}{*}{$\begin{array}{l}\text { Stress Locus of } \\
\text { Control }\end{array}$} & 370 & 79.04 & 20.34 & \multirow{2}{*}{0.05} & \multirow{2}{*}{$>0.05$} \\
\hline & 370 & 41.15 & 3.12 & & \\
\hline \multirow{2}{*}{ Stress Self-Concept } & 370 & 79.04 & 20.34 & \multirow{2}{*}{0.10} & \multirow{2}{*}{$>0.05$} \\
\hline & 370 & 115.02 & 11.64 & & \\
\hline \multirow{2}{*}{$\begin{array}{l}\text { Stress Achievement } \\
\text { Motivation }\end{array}$} & 370 & 79.04 & 20.34 & \multirow[b]{2}{*}{-0.01} & \multirow[b]{2}{*}{$>0.05$} \\
\hline & 370 & 49.12 & 4.33 & & \\
\hline
\end{tabular}

As also shown in Table 2, the correlation coefficient (r) between stress and achievement motivation is -0.01 , which also is not significant at 
the 0.05 probability level $\quad(\mathrm{N}=370, \mathrm{r}=-0.01, \mathrm{p}<0.05)$. From the foregoing results, it is concluded that there is no significant relationship between female teachers' level of stress and each of the personality traits of extraversion, locus of control, self concept and achievement motivation. The null hypothesis is therefore accepted.

\section{Hypothesis 2:}

This hypothesis states that personality variables of self-concept, extraversion, locus of control and extraversion will not significantly predict the stress level of female teachers.

To test the hypothesis, regression analysis was employed. The result of the regression analysis on the predictive contribution of the combination of the four independent variables and stress are summarized in Table 3.

Table 3: Summary of multiple regression analysis on the predictive contributions of independent variables to stress.

\begin{tabular}{|l|c|c|c|c|c|}
\hline \multicolumn{1}{|c|}{ Variables entered } & $\mathbf{R}$ & $\mathbf{R}$-square & $\begin{array}{c}\text { Adjusted } \mathbf{R} \\
\text { square }\end{array}$ & $\begin{array}{c}\text { Standard } \\
\text { error }\end{array}$ & $\mathbf{P}$ \\
\hline $\begin{array}{l}\text { Self concept } \\
\text { Locus of control } \\
\text { Achievement } \\
\text { motivation } \\
\text { Extraversion }\end{array}$ & 0.12 & 0.02 & 0.04 & 20.29 & $>0.05$ \\
\hline
\end{tabular}

Table 3 shows that using the four independent variables (self concept, locus of control, achievement motivation and extraversion) to predict stress yield a coefficient of multiple regression (R) of .12 and a multiple correlation square $\left(R^{2}\right)$ of .02 . These values are not statistically significant at 0.05 level. This implies that the combination of all the personality traits of Self Concept, Locus of Control, Achievement Motivation and Extraversion is not adequately predictive of teachers' level of stress. The predictive contributions of each of the personality traits are presented in Table 4.

As shown in Table 4 self concept and extraversion had t-values of 1.71 and -1.06 respectively also, the values of the beta weights for the two variables are -.09 and -.06 respectively. Locus of control and achievement motivation had $\mathrm{t}$-values and beta weights which are .50, .18, and .03, 01 respectively. These values are not significant at 0.05 level of confidence. 
Personality traits as predictors of stress among female

teachers in 0sun state teaching service

Popoola, B. I. \& Ilugbo, E. A.

Table 4: Relative contribution of the independent variables to the prediction of stress

\begin{tabular}{|l|c|c|c|c|c|}
\hline \multicolumn{1}{|c|}{ Variables } & B & $\begin{array}{c}\text { Standard } \\
\text { Error }\end{array}$ & Beta & $\mathbf{T}$ & $\mathbf{P}$ \\
\hline Constant & 95.38 & 22.06 & & 4.32 & .00 \\
\hline Self concept & -.16 & .09 & -.09 & -1.71 & .09 \\
\hline $\begin{array}{l}\text { Locus of } \\
\text { control }\end{array}$ & .17 & .35 & .03 & .50 & .62 \\
\hline $\begin{array}{l}\text { Achievement } \\
\text { motivation }\end{array}$ & $4.38 \mathrm{E}-02$ & .25 & .01 & .18 & .86 \\
\hline Extraversion & -.14 & .13 & -.06 & -.1 .06 & .29 \\
\hline
\end{tabular}

From the values of beta weights and t-ratio for each independent variable, it is shown that self concept had the highest contribution in the prediction of the dependent variable followed by extraversion, next is locus of control while achievement motivation had the lowest contribution in the prediction of the dependent variable. In the light of these findings, the appraisal of hypothesis two may be resolved that the combination of the personality variables of self-concept, locus of control, achievement motivation and extraversion did not significantly predict the stress level of female teachers.

Hypothesis 3: Marital status has no significant influence on the level of stress experienced by female teachers.

In testing the hypothesis, the teachers were classified into 3 groups: married, single and divorced. Table 5 shows the mean and SD stress ratings of female teachers based on their marital status.

Table 5: Female teachers stress ratings according to marital status

\begin{tabular}{|l|c|c|c|}
\hline Marital Status & Mean & Std. Deviation & N \\
\hline Married & 77.58 & 19.41 & 288 \\
\hline Single & 83.97 & 22.53 & 77 \\
\hline Divorced & 87.00 & 28.25 & 5 \\
\hline Total & 79.04 & 20.34 & 370 \\
\hline
\end{tabular}

As shown in Table 5, married female teachers had a mean stress rating of 77.58 and a standard deviation of 19.41; the singles had a mean stress rating of 83.97 and a standard deviation of 22.53 while those in the 
divorced group had the mean stress rating of 87.00 and a standard deviation 28.25. To determine the influence of marital status on stress ratings, these values were subjected to One-Way Analysis of Variance and the results obtained presented in Table 6:

Table 6: Influence of marital status on female teachers stress level

\begin{tabular}{|l|l|l|l|l|l|}
\hline Source of variance & Sum of squares & df & Mean & F & P \\
\hline Between groups & 2805.36 & 2 & 1402.68 & & \\
\hline Within groups & 149832.11 & 367 & 408.26 & 3.44 & $<0.05$ \\
\hline Total & 152637.47 & 369 & & & \\
\hline
\end{tabular}

From Table 6, the mean squares between groups and within groups are 2805.36 and 149832.11 respectively. These produced an F-value of 3.44 which is significant at the 0.05 level. From this, it is concluded that female teachers' marital status had a significant influence on their level of stress.

To determine which of the three groups had a superior rating over the others, the Scheffe's post hoc comparison of the mean stress rating of single, divorced and married female teachers was carried out. The results are presented in Table 7 .

Table 7: Multiple comparisons of stress ratings of female teachers based on marital status

\begin{tabular}{|c|l|l|l|l|l|c|}
\hline $\begin{array}{c}\text { marital } \\
\text { status }\end{array}$ & $\begin{array}{l}\text { marital } \\
\text { status }\end{array}$ & Mean & $\begin{array}{c}\text { Mean } \\
\text { difference }\end{array}$ & S.D & $\begin{array}{c}\text { Std. } \\
\text { error }\end{array}$ & Sig \\
\hline \multirow{2}{*}{ Married } & Single & 83.97 & $-6.34^{*}$ & 22.53 & 2.59 & $<0.05$ \\
\cline { 2 - 7 } & Divorced & 87.00 & -9.42 & 28.25 & 9.11 & $>0.05$ \\
\hline \multirow{2}{*}{ Single } & Married & 77.58 & $6.39^{*}$ & 19.41 & 2.59 & $<0.05$ \\
\cline { 2 - 7 } & Divorced & 87.00 & -3.03 & 28.25 & 9.32 & $>0.05$ \\
\hline \multirow{2}{*}{ Divorced } & Married & 77.58 & 9.42 & 19.41 & 9.11 & $>0.05$ \\
\cline { 2 - 7 } & Single & 83.97 & 3.03 & 22.53 & 9.32 & $>0.05$ \\
\hline
\end{tabular}

*The mean difference is significant at the .05 level.

From Table 7, multiple comparisons of the mean values of the three groups show a mean difference of 3.03 between single and divorced group. This difference is not significant at 0.05 level. Also, the mean difference of 9.42 obtained between divorced and married groups is not significant at 0.05 confidence level. However, when the mean value of single and married were compared a mean difference of 6.39 was 
Personality traits as predictors of stress among female

teachers in 0sun state teaching service

Popoola, B. I. \& Ilugbo, E. A.

obtained. This value is significant at 0.05 level. The sum total of these results is that single and married female teachers' stress ratings were significantly different from the other group. Specifically, married female teachers reported less stress than teachers who were single or divorced. Thus, the hypothesis which states that marital status has no significant influence on the level of stress experienced by female teachers is rejected.

\section{Discussion}

One of the major findings of this study is that majority of female teachers in Osun State Teaching Service had low level of stress. From the results, $80.3 \%$ of teachers had low stress level while $15.1 \%$ had medium and high stress level. These findings represent a departure from the results of various studies such as those of Cooper and Kelly (1993), Travers and Cooper (1991), Arroba and James (2002), Melhinsh (1998), Philips and Segel (1996), and Ravichandran and Rajendran (2007) which tend to have established that teachers generally had higher levels of stress than those of comparable occupational groups. However, the findings tend to corroborate those of Kriacou and Sutcliffe (1979) who found that a large proportion of teachers were very satisfied with teaching. Though a surprising result, it can be argued that the low level of stress reported by female teachers in this study probably points to the fact that the teaching profession in recent times is not as stressful for female teachers as it had been in the past. This tends to promote the growing assumption that teaching is the most suitable career for women because it gives them ample opportunity to take care of their spouses and children. Female teachers in Osun State are not an exception. Most often they close early enough from school to take care of their children and even engage in other business ventures.

The low level of stress experienced by female teachers in this study may also be attributable to recent efforts by government to improve teachers' working conditions in the study area. More classrooms are being built by government to solve the problem of overcrowded classrooms and dilapidated facilities. Shortly before this study was carried out, the Federal Government recruited a substantial number of teachers to work in primary schools while the Osun State Government also employed a significant number of teachers (popularly called Oyin Corps) to complement the efforts of teachers in schools where there is acute teacher shortage in the State. All these and other reasons may have reduced the work stress of teachers at the time this study was conducted. 
The results of the second hypothesis showed that there was no significant relationship between stress and each of the selected personality characteristics. In more specific terms, the personality traits of self concept, extraversion, locus of control and achievement motivation did not have significant relationship with stress. The implication of this finding is that personality traits could not be relied upon to significantly predict the stress level of female teachers. This finding is at variance with the findings of Bolger and Shilling (1991) which show that personality traits have a pervasive influence on the perceptions of stress and distress. The implication of this is that none of the personality variables investigated in this study is a significant predictor of stress. This probably suggests that rather than focus on personality variables, there is the need for researchers to investigate other non-personality variables to determine those that are likely to be predictive of stress among female teachers.

Another finding of this study is the influence of marital status of stress experienced by female teachers. The results indicated that female teachers' marital status had a significant effect on reported levels of stress. It is noteworthy that married female teachers had the least stress rating compared to singles and divorced female teachers. A plausible explanation for this could be the importance attached to married life among the people. A single or divorced lady is constantly subjected to societal pressure, which could become in itself a potential source of stress. It is also likely that married female teachers experienced less stress because they received some psychological support from their spouses, which enabled them to cope with stress on their jobs. Not only this, marital adjustment skills and shared responsibility at home might be other reasons why married female teachers had the least stress rating.

\section{Conclusion}

Teachers are the catalysts that foster changes in education. They transmit the values of the society to the youths and they are significant in the lives of the students they teach. If they have negative emotional responses, there is every likelihood that not only would they perform ineffectively, they would transfer some of these feelings to the students they teach. This would have negative consequences on education and the desired development in this country.

Though the results of the study on the low level of job stress among female teachers seem to deviate from what is found in popular literature on the topic, the paper has brought into focus the need to re-examine 
Personality traits as predictors of stress among female

teachers in 0sun state teaching service

Popoola, B. I. \& Ilugbo, E. A.

widespread belief that teaching is an extremely stressful occupation. It is likely that recent improvements in the working conditions of teachers in the study area have contributed immensely to the low stress level reported by teachers. However, there is need for caution in generalizing the findings of the study to all categories of teachers. Since the study relies heavily on information obtained from a small sample of teachers, the findings might not portray an accurate picture of the occupational stress experienced by all teachers in the study area. It is not unlikely that if a larger sample of teachers had been used, the findings would have been different. However, the study is significant in that it represents a step towards re-examining previously held beliefs about the magnitude of psychological and occupation stress experienced by practicing teachers. More importantly, this study has shown that the prominence given to personality variables in the explanation of stress experienced by professional teachers may have been misplaced.

\section{References}

Akande, A. (1989). Nigerian Teachers' Occupational Stress and their career choices. Nigerian Journal of Counselling and Development, 4. 66-72.

Akinboye J. O., \& Adeyemo, D. A. (2002). Stress at home and workplace. Ibadan: Stirling Horden Publishers.

Arroba, T., \& James, K. (2002). Pressure at work: A survival guide (2nd Ed.). Maidenhead: McGraw-Hill.

Baghy, R. M; \& Rector, N. A. (1988). Self-criticism, dependency, and the five factor model of personality in depression: Assessing construct overlap. Personality and Individual Differences, 24, 895-897.

Balogun, O. R. (1987). Factors affecting students' academic performance in KUASCE. Unpublished P.G.D.E. Project, University of Ilorin, Ilorin.

Bolger, N; \& Zuckerman, A. (1995). A framework for studying personality in the stress process. Journal of Personality and Social Psychology, 69, 890 902.

Boyinbode, E.R. (1988). Personality correlates of item response changing behaviour in two objective test formats. Unpublished Doctoral Thesis, University of Ibadan, Ibadan.

Cooper, C. \& Kelly, M. (1993). Occupational stress in head teachers: A national UK study. British Journal of Educational Psychology, 63, 130143

Dibu-Ojerinde, O. O. (1984). Factor analytic study of Tennessee self-concept scale. Unpublished M.A. Thesis, University of Ife, Ile-Ife. 
Evers, W., Tomic, W., \& Brouwers, A. (2005). Does equity sensitivity moderate the relationship between self-efficacy beliefs and teacher burnout? Representative Research in Social Psychology, 25, 35-46

Eyo, I. E. (1986). Nigerian adaptation of Herman's Questionnaire Measure of Achievement Motivation. Nigerian Journal of Psychology. 5, 52-71.

Eysenck, H.J. (1956). The Questionnaire Measure of Neuroticism and Extraversion. Revista de Psicologia. 50, 133 - 140.

Fitts, W.H. (1964). The Tennessee Self-Concept Scale. Nashville, Tennessee: Counsellor Recording and Tests.

Gelvin, A.M. (2007). Identifying the types of student and teacher behaviours associated with teacher stress. Teaching and Teacher Education, 23 (5), $624-640$.

Gibson, J. L. John, M. Ivancevich and James, H. Donnelly (1988). Organizational behaviour, structures processes $\left(8^{\text {th }}\right.$ ed.). Piano, Tex, BPI.

Herman, H.J.M. (1970). A Questionnaire Measure of Achievement Motivation. Journal of Applied Psychology, 54, 353 - 363

Houston, B. K. \& Vavak, C. R. (1991). Hostility, developmental factors, psychological correlates, and health behaviours. Health Psychology, 10, 9-17.

Kokkinos, C.M. (2006). Factor structure and psychometric properties of the Maslach Burnout Inventory - Educators survey among elementary and secondary school teachers in Cyprus. Stress and Health: Journal of the International Society for the Investigation of Stress, 22, 25-33.

Kokkinos, C.M. (2007). Job stressors, personality and burnout in primary school teachers. British Journal of Educational Psychology, 77 (1), 229 243

Kokkinos, C.M., Panayiotou, G., \& Dazoglou, A.M. (2005). Correlates of teacher appraisal of students' behaviour. Psychology in the Schools, 42, 79-89.

Kriacou, C., \& Sutcliffe, J. (1979). Teacher stress and satisfaction. Educational Research, 21, 86-89.

Lhospital, A.S. \& Gregory, A (2009). Changes in teacher stress through participation in pre-referral intervention teams. Psychology in the Schools, 46 (10), 1098 - 1112

Melhinsh, A. (1998). Executive health. London: Business Books.

O'Connor, P.R. \& Clarke, V.A. (1990). Determinants of teacher stress. Australian Journal of Education, 34 (1). 41-51.

Odeyemi, A. A. (1995). Personality correlates of guessing behaviour in three multiple choice test formats. Unpublished M. A. Thesis, Obafemi Awolowo University, Ile-Ife. 
Personality traits as predictors of stress among female

teachers in 0sun state teaching service

Popoola, B. I. \& Ilugbo, E. A.

Phillips, J., \& Segal, L. (1996). Pretian Strategy and Organization Support Systems: Implication for Stress Management at workplace. Journal of Social Psychology, 7 (2) 28-39.

Popoola, B. I. (2003). Personality characteristics, socio-demographic variables and work attitudes as correlates of school counsellor effectiveness in selected states of South Western Nigeria. Unpublished Ph.D Thesis, Obafemi Awolowo University, Ile-Ife.

Raedeke, T.D., \& Smith, A.L. (2004). Coping resources and athlete burnout: An examination of stress mediated moderation hypotheses. Journal of Sport and Exercise Psychology, 26, 525-541.

Ravichandran, R. \& Rajendran, R. (2007). Perceived sources of stress among teachers. Journal of the Indian Academy of Applied Psychology, 33 (1) 133-136.

Riolli, L., \& Savicki, V. (2003). Optimism and Coping as Moderators of the Relation Between Work Resources and Burnout in Information Service Workers. International Journal of Stress Management, 10, 235252.

Rosenberg, T., \& Pace, M. (2006). Burnout among mental health professionals: Special considerations for the marriage and family therapist. Journal of Marital and Family Therapy, 32, 89-99.

Rotter, J. B. (1966). Generalized expectancies for internal versus external control of reinforcement. Psychological Monographs, 80 (No 609).

Schermerhorn, J. R., Hunt, J. G \& Osborn, R. N. (2005). Organizational behavior, (9th ed). Hoboken, NJ: John Wiley and Sons.

Selye, H. (1974). The stress of life. New York: McGraw-Hill.

Thomas, N., Clarke, V. \& Lavery, J. (2003). Self-reported work and family stress of female primary teachers. Australian Journal of Education, 47 (1), $73-87$

Travers, C.J., \& Cooper, C.L. (1991).Stress and status in teaching: An investigation of potential gender-related relationships. Women in Management Review, 6 (4),

Van Dierendonck, D., Garssen, B., \& Visser, A. (2005). Burnout prevention through personal growth. International Journal of Stress Management, $12,62-77$

Wahlund, H., \& Nerel, G. (1976). Work environment of white-collar workers - Work, health, well-being. Stockholm: The Central Organization of Salaried Employees in Sweden. 